\title{
Response of a Light Aircraft Under Gust Loads
}

P. Chudý

This project presents work performed by the Institute of Aerospace Engineering, Brno University of Technology. The primary purpose of this work was to estimate the aeroelastic response of a light aircraft under gust loads. In the past, the gust response has been investigated using the Pratt - Walker formula. This formula is derived from the response of a rigid airplane to a discrete gust. However, the Pratt-Walker formula does not capture either the stochastic nature of continuous turbulence or the effects of structural flexibility. The analysis described here was performed using the advanced FEM software package MSC Nastran.

Keywords: gust load, finite element, aeroelasticity, frequency response, continuous turbulence.

\section{Nomenclature}

$\left[M_{h h}\right] \quad$ Modal Mass Matrix

$\left[K_{h h}\right] \quad$ Modal Stiffness Matrix

$M \quad$ Mach Number

$k \quad$ Reduced Frequency

$c \quad$ Reference Length

$\left[Q_{h h}(m, k)\right]$ Unsteady Aerodynamic Force Matrix

$\omega \quad$ Circular Frequency

$f \quad$ Frequency

$g \quad$ Structural Damping, Acceleration due to gravity

$\rho \quad$ Air density

$V \quad$ Airplane Velocity

$\left\{u_{h}\right\} \quad$ Modal Amplitude Vector

$\{P(\omega)\} \quad$ Applied Gust Loading

$\bar{A} \quad$ Root-mean-square value of the response

$N_{0} \quad$ Expected number of zero crossings with positive slope per unit time

$U_{0} \quad$ Gust velocity

a Slope of wing lift curve per radian

$m \quad$ Mass of the sailplane

$S \quad$ Design wing area

$k \quad$ Gust alleviation factor

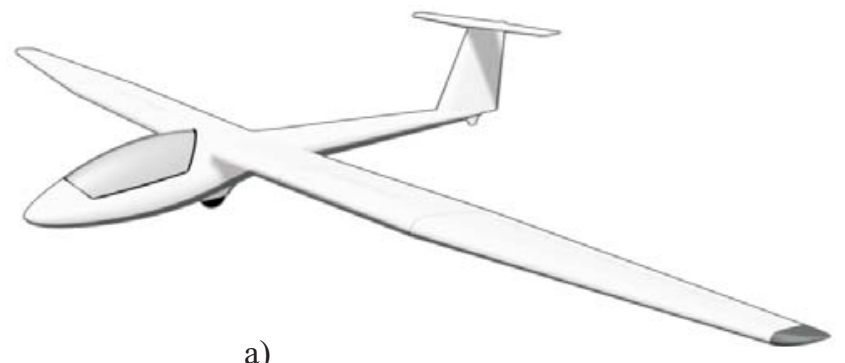

a)

Dimensions:

$\begin{array}{ll}\text { Span } & 14 \mathrm{~m} \\ \text { Length } & 6.7 \mathrm{~m} \\ \text { Height } & 1.4 \mathrm{~m} \\ \text { Wing Area } & 11 \mathrm{~m}^{2} \\ \text { Wing Aspect Ratio } & 17.8\end{array}$

$\mu \quad$ Non-dimensional mass ratio

$l_{m} \quad$ Mean geometric chord of the wing

\section{Introduction}

The aerospace industry tends to deliver optimized products to specific areas of aeronautical use. There is a strong desire to reduce the primary and operational costs of a new product in order to make interesting to potential customers. Since airplanes, even the smallest and simplest, are the result of a complex design approach that has required long-term development, it is occasionally useful to consider a reevaluation of some design features to improve the specific properties and qualities of planes. Within the guidelines of the 'rational analysis' required by the regulations, this paper provides a comparative analysis of gust load estimation methods. Through a closer understanding of the gust phenomenon we will be able to make a more precise prediction of the gust loads acting on the structure.

\section{Basic gust studies}

In general, there are two methods widely accepted by the aeronautical authorities. Both of them are implemented in the world leading sets of aeronautical safety requirements.

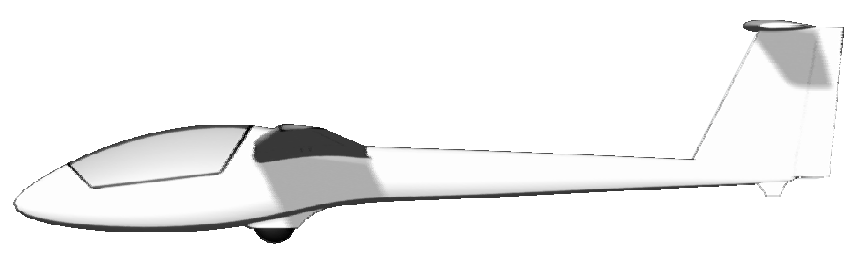

b)

Fig. 1 
The deterministic method describes the 'worst case' atmospheric gust approach. The nature of the gust field is reduced to a form of one dominant discrete gust with closer shape specification. The second approach belongs to the family of statistical methods. The atmosphere is described by the power spectral density function and transforms the problem from the time to a frequency domain. For both methods a set of gust velocities for specific flight conditions has been defined. From several types of gust PSD functions the Von Karman and Dryden function are widely used. Both of them describe a distribution of the gust energy in a frequency domain.

\section{Dimensions and Performances}

For the purposes of this sensitive analysis a glider has been used. Its lightweight structure suitably represents an optimized aeronautical design. The high aspect ratio wing has been assumed to be equipped only with ailerons, without any further high lift or drag increasing devices. This concept led into a smooth variation in torsion and bending stiffness. The fuselage features a fully-equipped single pilot cockpit. The pilot's physical properties were chosen according to the published recommendations. The structure was assumed to be full metal. Symmetric geometrical, aerodynamic and inertial properties proved fruitful for further simplification procedures involved in the preprocessing stage of the analysis. The basic data is listed under Fig. 1.b. Fig. 1.a shows a 3D drawing of the glider.

\section{Finite element model}

Fig. 2.a shows the resulting MSC/NASTRAN full span model, which was used in the PSD gust analysis. The stiffness properties are contained in the beam elements, which run along the elastic axis of the wing, fuselage and tail unit. The model mass is contained in the concentrated masses which lie close to the elastic axes. Rod elements connect the grids at the leading and trailing edges with the grids at the elastic axis. The purpose of the grid connection is to provide modal shape displacement so that the motion can be transferred onto the aerodynamic surfaces via the splines.

\section{Aerodynamic panels}

Fig. 2.b shows the structural grids and aerodynamic panels used in the full span model. The aerodynamic conditions are defined by the Doublet - Lattice Method (DLM). The wing was divided into dorsal and ventral parts. The horizontal and vertical tail also features aerodynamic panels. The dorsal wing panels have 8 chord-wise boxes and 12 span-wise boxes; the ventral wing panels also have 8 chord-wise boxes and 12 span-wise boxes. The vertical tail has 8 chord-wise boxes and 8 span-wise boxes. The horizontal tail features 8 chord-wise boxes and 10 span-wise boxes for each half.

The modal displacements of the aerodynamic boxes are related to the displacements of the structural grids by a surface splining technique. The aerodynamic theory (DLM) used in this case does not allow the definition of camber, twist or angle of incidence, even as they affect the gust loading under real circumstances.

The theoretical basis of the DLM is linearized aerodynamic potential theory. The undisturbed flow is uniform and is either steady or gusting harmonically. All lifting surfaces are assumed to lie parallel to the flow.

\section{Analysis method}

Unsteady modal aerodynamic forces and gust loads are calculated in the frequency domain. Structural stiffness, mass and damping are modeled using rigid body and elastic modes with structural damping. The resulting aeroelastic modal equations of motion can be written in the form:

$\left[-\omega^{2}\left[M_{h h}\right]+(1+i g)\left[K_{h h}\right]-\frac{1}{2} \rho V^{2}\left[Q_{h h}(M, k)\right]\right]\left\{u_{h}\right\}=\{P(\omega)\}$

\section{Continuous turbulence}

Atmospheric turbulence is in fact a continuous phenomenon, which subjects the aircraft to repeated gustiness. Since the application of high strength alloys for extremely stressed parts, which required more precise fatigue examination, the question of the relevance of the discrete gust formula has become more important. To reflect the continuous character of atmospheric turbulence, statistical methods have been developed.

In the primal phase of the gust responses evaluation, the Continuous Turbulence approach was selected. The power spectral density (PSD) of the gust was represented by a Von Karman model (Fig. 3).

The input data requirements were generated for a single set of flight conditions. Modes spanning the frequency band up to $60 \mathrm{~Hz}$ were included in the analysis. The PSD of re-
STRUCTURAL MODEL

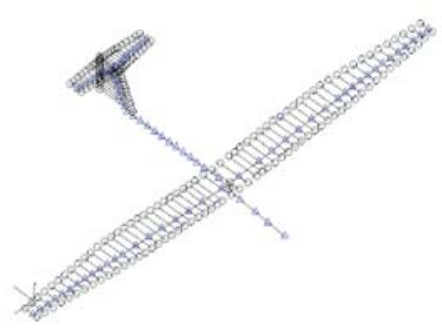

a)

\section{AERODYNAMIC PANELING}

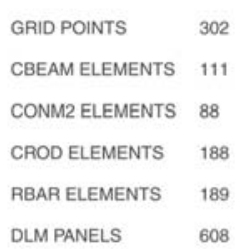

DLM PANELS 608

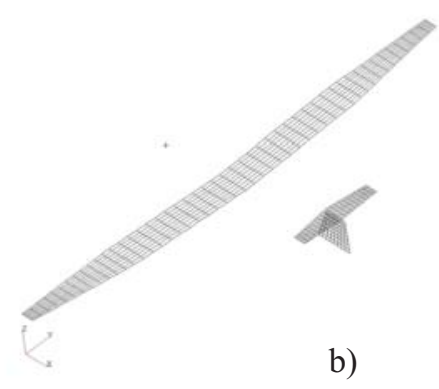

Fig. 2 
sponse qualities such as moments and torques at critical points of the structure were generated and plotted versus a range of frequencies covering the elastic mode of vibration.

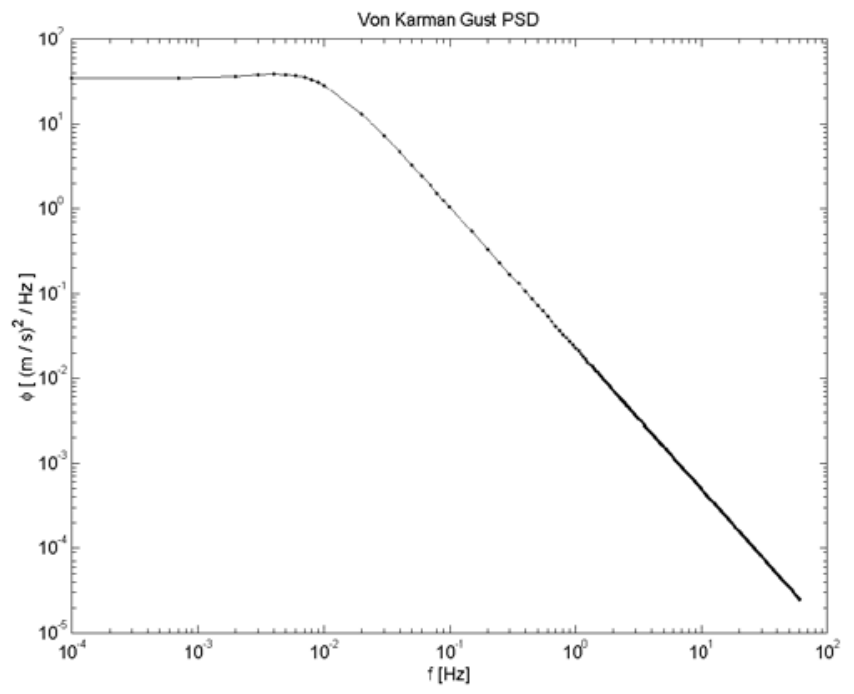

Fig. 3: The power spectral density of the gust (Von Karman model)

The computation scheme features the transfer function theorem. For single Input/Output systems, the PSD function of the response quantity, $\psi(\omega)$, is related to the PSD function of the source, $\Phi(\omega)$, by

$$
\psi(\omega)=|H(i \omega)|^{2} \Phi(\omega)
$$

where $H(i \omega)$ is the frequency response function.

\section{Flight conditions}

Data required for the random dynamic loads analysis was inserted into MSC/NASTRAN Bulk Data deck.

Table 1 shows the flight conditions for analysis:

Table 1: Flight conditions for continuous turbulence analysis

\begin{tabular}{|l|c|}
\hline Altitude & $1000.0 \mathrm{~m}$ \\
\hline True Air Speed & $44.0 \mathrm{~m} . \mathrm{s}^{-1}$ \\
\hline Dynamic pressure & $1076.06 \mathrm{~Pa}$ \\
\hline Mach number & 0.1308 \\
\hline
\end{tabular}

Table 2 defines the properties of the Von Karman gust SD.

Table 2: The properties of the Von Karman gust

\begin{tabular}{|c|c|}
\hline$L$ (Scale of turbulence) & $2500.0 \mathrm{ft}$ \\
\hline$W_{G}($ RMS gust velocity) & $1 \mathrm{~m} \cdot \mathrm{s}^{-1}$ \\
\hline
\end{tabular}

\section{Response qualities investigated}

A normal mode analysis was performed to obtain the weight and center of gravity (CG) location. For the full span case the CG is at the centerline, and both symmetric and anti-symmetric modes are involved. The loads in all performed analyses were calculated at grid point 101 (wing root).

The loads investigated were:

- horizontal bending moment (M1),

- vertical bending moment (M2),

- total web torque $(\mathrm{T})$.

\section{Results and discussion}

The PSD of the investigated response qualities at the wing root is shown in Fig. 4-Fig. 6. The largest response for bending moment M2 occurs at a frequency of about $0.95 \mathrm{~Hz}$, which is the frequency of the first bending mode. A smaller peak of M2 response occurs at a frequency of $5.35 \mathrm{~Hz}$. Higher frequency modes do not influence the M2 response. The moment M1 response has its highest value at a frequency of 17.1 Hz. The torque PSD has its peak at a frequency of $0.9 \mathrm{~Hz}$ and multiple other smaller peaks.

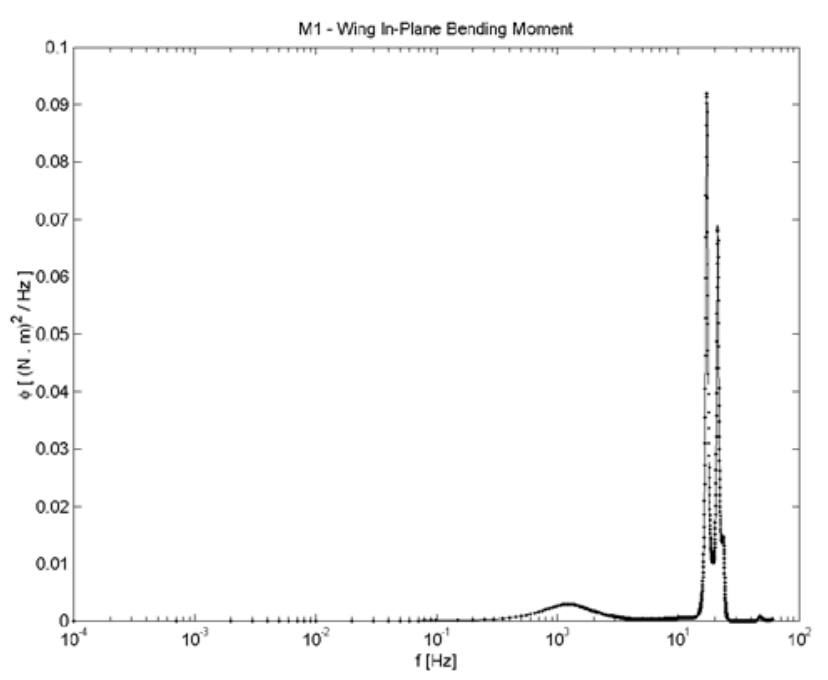

Fig. 4: Power spectral density of M1 at the wing root

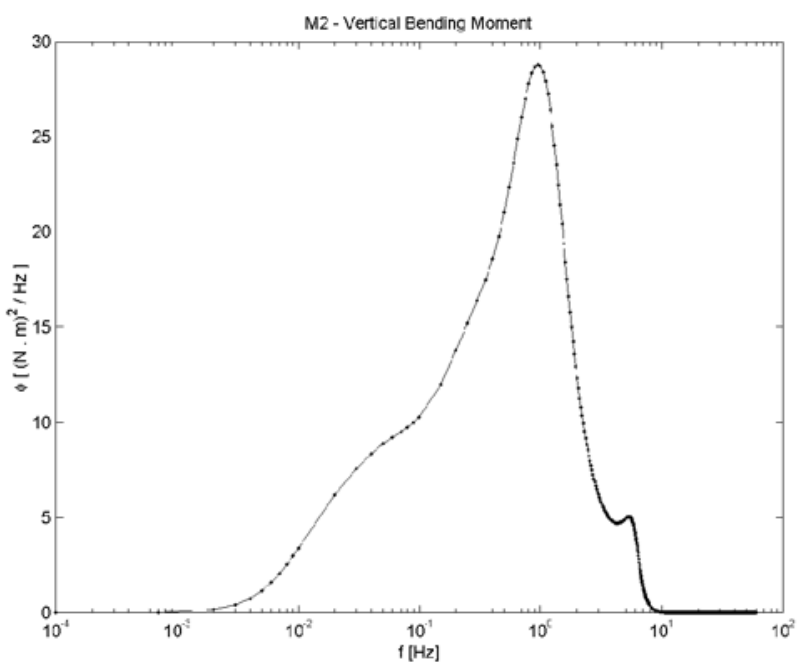

Fig. 5: Power spectral density of M2 at the wing root 


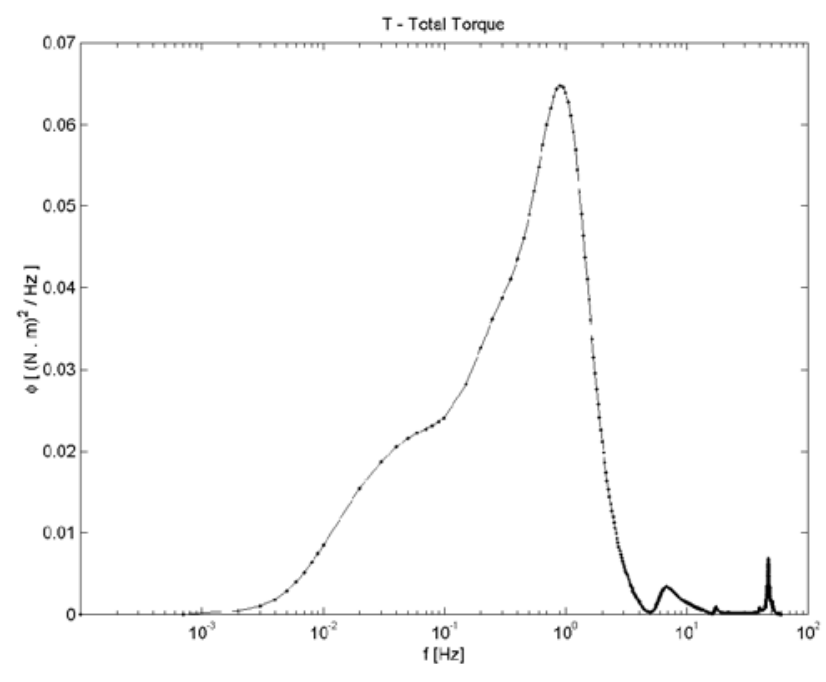

Fig. 6: Power spectral density of $\mathrm{T}$ at the wing root

The following integrals were used to calculate the probability parameters of the response quantities.

$$
\begin{aligned}
& \bar{A}=\sqrt{\int_{0}^{\infty} \Phi(f) \mathrm{d} f} \\
& N_{0}=\sqrt{\frac{\int_{0}^{\infty} f^{2} \Phi(f) \mathrm{d} f}{\int_{0}^{\infty} \Phi(f) \mathrm{d} f}}
\end{aligned}
$$

A simple program was written for calculation of the integrals. The integrals were evaluated numerically using a trapezoidal rule. The resulting probability parameters are listed in Table 3.

Table 3: Summary of the probability parameters at the wing root station

\begin{tabular}{|c|c|c|}
\hline Type of response & $\bar{A}(\mathrm{~N} \cdot \mathrm{m})$ & $N_{0}(\mathrm{~Hz})$ \\
\hline $\mathrm{M} 1$ & 0.502 & 20.23 \\
\hline $\mathrm{M} 2$ & 8.263 & 3.105 \\
\hline $\mathrm{T}$ & 0.389 & 20.12 \\
\hline
\end{tabular}

\section{Discrete gust analysis}

Considerable evidence can be found indicating that most severe gusts occur more or less as individual gusts. The deterministic computational method describes the 'worst case' atmospheric gust approach, where the nature of the gust field has been reduced to the form of one dominant discrete gust with close shape specification. As stated at the beginning of this paper, gust loads due to a discrete gust have usually been evaluated using the static Pratt-Walker formula. This formula was, for a long time the basic tool for gust load evaluation. In the calculation of static gust loads, a single gradient distance of 12.5 chords is specified. The actual gradient distance is not very important from the static gust viewpoint. The JAR 22 gust load formula for avertical gust is, essentially,

$$
n=1 \pm\left[\frac{\frac{1}{k} \rho_{0} \cdot U_{0} \cdot V \cdot a}{\frac{m \cdot g}{S}}\right]
$$

in conjunction with

$$
k=\frac{0.88 \cdot \mu_{g}}{5.3+\mu_{g}}, \quad \mu_{g}=\frac{2 \frac{m}{S}}{\rho \cdot l_{m} \cdot a} .
$$

Inclusion of the inertia forces associated with elastic-mode accelerations indicates dynamic gust loads. Since it is not clearly defined how the gust velocity varies with the gradient distance, the dynamic load determination for the glider gust response was performed using only a 12.5 chord gust profile. The excitation waveform was used in the following form:

$$
U=\frac{U_{0}}{2}\left[1-\cos \left(\frac{\pi \cdot V}{H \cdot t}\right)\right] \text {. }
$$

The dynamic response is indeed sensitive to gradient length. For transport-type aircraft, this issue is solved by a defining the gust gradient range and velocity profiles included in the analysis. The presence of an attenuation factor affects the higher frequency modes. Typical structural loads due to a discrete gust tend to have much lower values than for a transport aircraft. Lifted or plunged vertically during a uniform discrete gust, the glider encounters little inertia resistance. Conversely, accelerations in response to discrete gusts tend to be larger than for heavier transports. The essential feature of the analysis is the time history solution of the response.

The MSC/NASTRAN semi span model was used for further discrete gust analysis. The model was structurally constrained to reflect symmetrical motions at the aircraft centerline. The DLM was used to compute the unsteady aerodynamics. The parameters for a single flight condition are listed in the table 4 . The gust velocity used in the analysis is taken from [9].

Table 4: Flight conditions for discrete gust analysis

\begin{tabular}{|c|c|}
\hline Altitude & $1000.0 \mathrm{~m}$ \\
\hline True Air Speed & $44.0 \mathrm{~m} \cdot \mathrm{s}^{-1}$ \\
\hline Dynamic pressure & $1076.06 \mathrm{~Pa}$ \\
\hline Mach number & 0.1308 \\
\hline Gust Velocity, $U_{0}$ & $15.0 \mathrm{~m} \cdot \mathrm{s}^{-1}$ \\
\hline
\end{tabular}

\section{Results and discussion}

Traditionally, the vertical bending moment, vertical shear force and torsion moment along the wing were computed. Generally we were interested in the points of highest magnitude. The in-plane loads are usually much smaller and have therefore been regarded to be inconsequential.

For the purposes of this analysis two points have been selected for outputting load and acceleration time history. 
These points were placed at the CG and at the wing root. Fig. 7 shows the semi span model with the response monitoring locations.

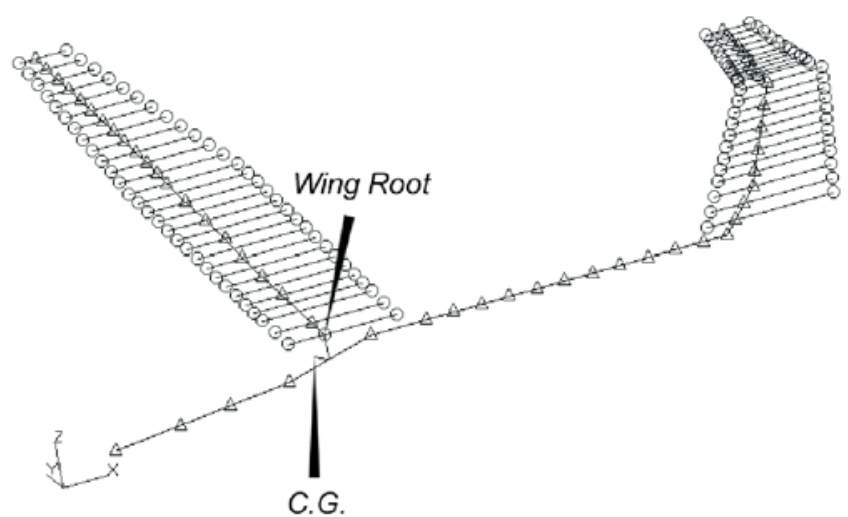

Fig. 7: Monitoring locations

The time responses of the vertical bending moment, vertical shear force and torsion moment at the wing root are shown in Fig. 8-Fig. 10. Bending moment M2 has its highest peak at a time of 0.47 seconds. Vertical shear force V2 has a peak of magnitude $4200 \mathrm{~N}$ at a time of 0.47 seconds. The torsion moment has its highest response at a time of 0.47 seconds. Fig. 11 shows the acceleration time history. The highest CG acceleration is achieved at a time of 0.47 seconds. The maximum acceleration that the glider is exposed to has a value of $4.56 \mathrm{~g}$.

The solution of the static gust formula is not included in this paper. The resulting bending moment, vertical shear force and load factor increment are listed in Table 5. A comparison with the specific values in Table 5 shows fairly good agreement between the two discrete gust analysis methods.

Table 5: Comparison of discrete gust solutions

\begin{tabular}{|l|c|c|c|}
\hline Type & $\Delta \mathrm{n}[\mathrm{g}]$ & $\mathrm{V} 2[\mathrm{~N}]$ & $\mathrm{M} 2[\mathrm{~N} . \mathrm{m}]$ \\
\hline Static & 4.53 & 4250 & 16500 \\
\hline Dynamic & 4.56 & 4200 & 16460 \\
\hline
\end{tabular}

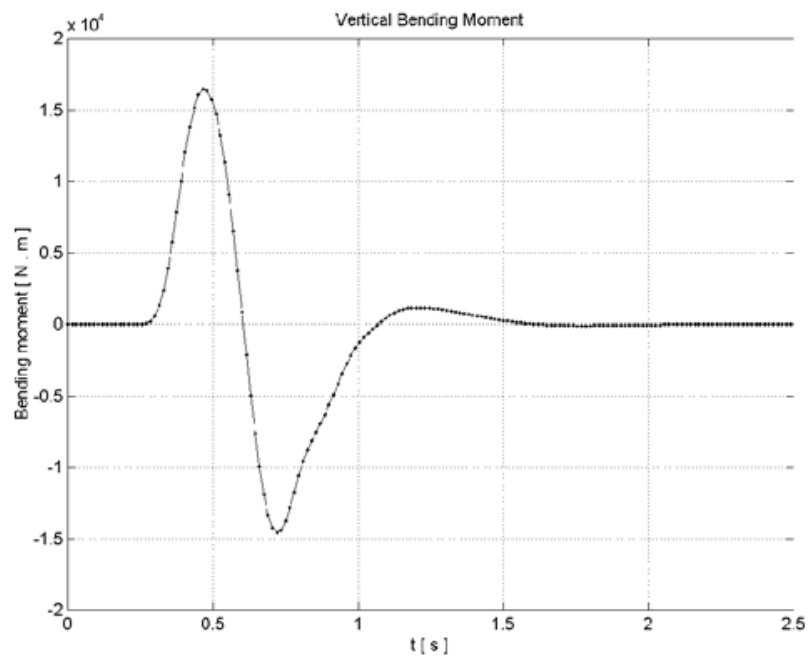

Fig. 8: Time history of vertical bending moment M2 at the wing root

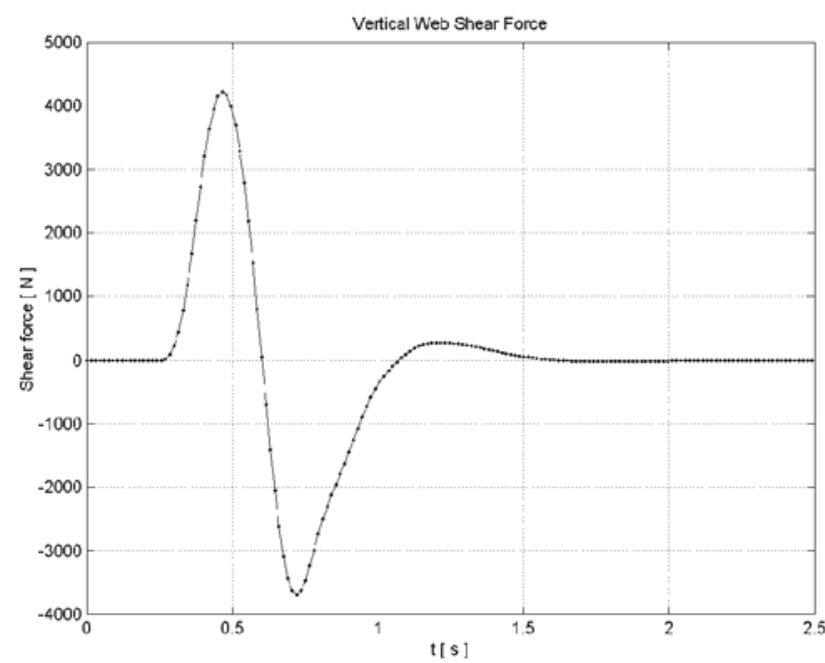

Fig. 9: Time history of vertical shear force V2 at the wing root

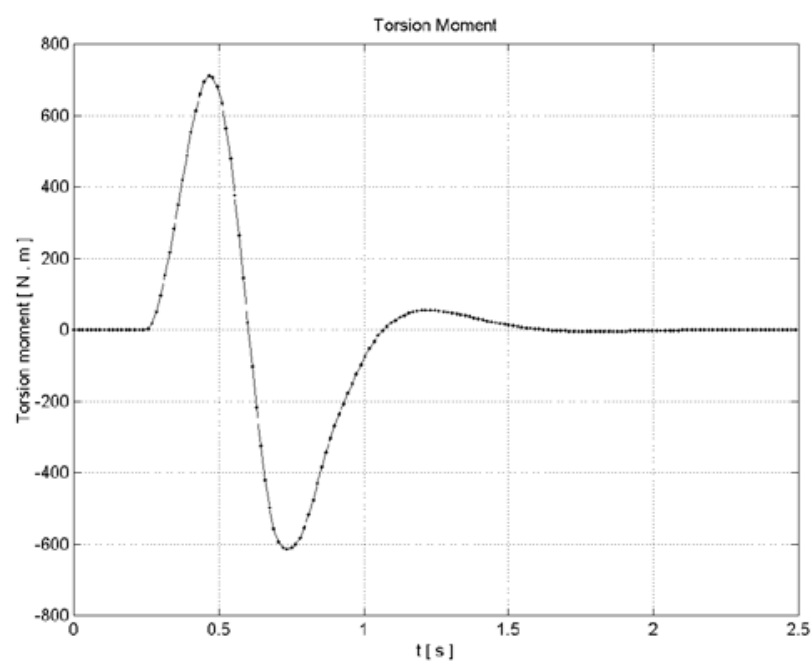

Fig. 10: Time history of the torsion moment at the wing root

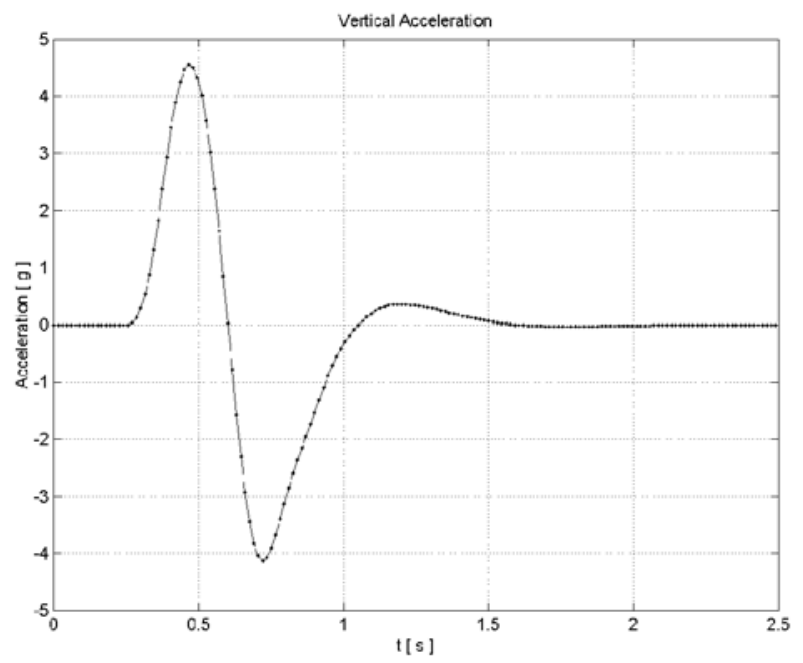

Fig. 11: Time history of acceleration at CG 
The advantage of the dynamic discrete gust approach is in the solution of its time history Fig. 11 shows that the glider's motion is convergent - naturally stable. This is a very important conclusion from the flight mechanics point of view.

\section{Conclusions}

The results clearly indicate the qualitative and quantitative part of the glider computational gust response analysis. For continuous turbulence, the analysis returns the values of $A$ and $N_{0}$. The $A$ value is extremely low for static design purposes, but can be further used in fatigue properties evaluation. The maximum gust load factors and corresponding structural loads, obtained separately for the dynamic and also the static gust response, were found to be in good agreement. The Pratt-Walker formula seems to be a sufficient tool for glider gust load estimation, provided that we are satisfied with only one gust gradient solution run for the dynamic response. The dynamic discrete gust approach using the 1-cos formula will be further extended, using some features from the certification procedures for a heavier aircraft class.

\section{References}

[1] Pratt K. G., Walker W. G.: A Revised Gust-Load Formula and a Re-Evaluation of V-G Data Taken on Civil Transport Airplanes From 1933 to 1950. NACA Report 1206, 1954.

[2] Rodden W. P., Johnson E. H.: MSC/NASTRAN Aeroelastic Analysis User's Guide. The MacNeal-Schwendler Corporation.
[3] Hoblit F. M.: Gust Loads on Aircraft: Concepts and Applications. AIAA Education Series, AIAA, Washington, 1988.

[4] Eight NASTRAN User's Colloquium, NASA-CP-2131.

[5] Hodges D. H., Pierce G. A.: Introduction to Structural Dynamics and Aeroelasticity. Cambridge Aerospace Series, 2002.

[6] Bisplinghoff R. L., Ashley H., Halfman R. L.: Aeroelasticity. New York: Dover Publications, 1996.

[7] Donely P.: Summary of Information Relating to Gust Loads on Airplanes. NACA Rep. 997, 1950.

[8] Moštěk D.: Analýza Aeroelastických Vlastností Kluzáku L-33 Systémem MSC/NASTRAN. Brno, 1997.

[9] JAR-22: Sailplanes and Powerd Sailplanes, 2001.

[10] Naser A. S., Pototzky A. S., Spain C. V.: Response of Alliance 1 Proof-of-Concept Airplane Under Gust Loads. NASA/CR-2001-210649, 2001.

[11] Locke J. E.: Balanced Continuous Turbulence Gust Loads Using Solution 146, 1999.

Ing. Peter Chudý

e-mail: peter.chudy@pobox.sk

Institute of Aerospace Engineering

Brno University of Technology

Technická 2

61669 Brno, Czech Republic 